IBT Journal of Business Studies

Volume 14(2), 53-66, 2018

\title{
The Role of E- Recruitment in Attracting Potential Candidates- Evidence from Fresh Graduate Job Seekers
}

\author{
Muhammad Hafeez ${ }^{l}$ \\ Umar Farooq ${ }^{2}$ \\ Muhammad Ziaullah ${ }^{3}$ \\ Muhammad Arif ${ }^{4}$ \\ Samra Ashraf
}

\begin{abstract}
The study aims to investigate the effectiveness of an online recruitment system and its impact on organizational attraction among fresh graduate job seekers. A sample comprised of 302 fresh graduate job seekers from well-known HEC recognized business schools in the Lahore region is selected using Stratified Random Sampling. Since the data is not normal, the Kruskill Wall is test of mean differences is applied to compare the effectiveness of e-recruitment with traditional methods of recruitment. Furthermore, the Macro process tool of Regression analysis is used to examine the matter of cost effectiveness, easy to use and website quality. Findings of regression results confirm that e-recruitment has a positive influence on organizational attractionand cost effectiveness and easy to use mediate the relationship between e-recruitment and organizational attraction. However, positive relation between e-recruitment and organizational attraction depends on the quality of the recruitment website which depicts that Sitequal (Website Quality) moderates the relationship between e-recruitment and organization attraction. Thus, this study offers valuable findings for managers that aim to adopt E-recruitment systems in their hiring process.
\end{abstract}

KEYWORDS: Recruitment, E-Recruitment, Cost Effectiveness, Easy to Use, Site quality, Organizational Attraction

1- Leads Business School \& School of Business Administration, Lahore Leads University, Lahore Pakistan \& Shaheed Banzir Bhutto University, Shaheed Banzir Abad, muhammadhafeez@,gmail.com

2- Leads Business School, Lahore Leads University, Lahore Pakistan, umar_farooq@outlook.com

3- Department of Business Administration, Ghazi University, D.G. Khan, mziaullah@gudgk.edu.pk

4- School of Business Administration, Shaheed Banzir Bhutto University, Shaheed Banzir Abad, muhammad.arif2011@yahoo.com

5- Faculty of Computer Sciences, Lahore Leads University, Lahore Pakistan, samra.ashraf01@gmail.com 


\section{INTRODUCTION}

Organizational attraction is rapidly growing concept that has become a focus point in the academic research society as well as in business divisions. The importance of organizational attraction comes from noteworthy elements that could likely impact the future execution and benefit of an organization. Organizational attraction is a multidimensional and extremely confusing subject that has been talked about over the last twenty years. Tsai and Yang (2010) stated that organizational attraction as the willingness of candidates to seek after occupations and to acknowledge employment offers in an organization. The decision of potential applicants to apply for a job could be affected by the source/medium of recruitment (Blackman, 2006). Hoye and Lievens (2005) explain that recruitmentrelated data sources and their characteristics can be essential forerunners for organizational attractiveness. Both internal and external recruitment sources have an impact on job hunters' attraction towards organizations and their potential employment decisions. The organizations which adopt an e-recruitment strategy get to be conspicuous among the job seekers; resultantly skilled job seekers will want to become part of such an organization (Hafeez and Farooq, 2016).

Business has been intensely changed by rapid developments in technology. The growing number of organizations and individuals who use internet explicitly reveal the strong reliance on technology. The incessant increase in the volume of literature that seeks to discover the impact of latest technology advancements and execution on the efficiency of business is also evidence for the effects of technology on business operations (Cullen, 2001; Dessler, 2001; Dineen et al., 2004). As technology affects all operations and functions of business, so has it affected the recruitment process. Subsequently, the process in which information technology is used to improve the recruitment process is called e-recruitment (Tong and Sivanand, 2005). The number of internet users is increasing rapidly, almost $80 \%$ (four out of five) of organizations use an e-recruitment system to hire new employees (Musa et al., 2006). It was reported that the E-recruitment method is used by $75 \%$ of Human resource managers in developed countries in contrast to traditional recruitment methods (Anonymous, 2000). Smith (2005) pointed out that $65 \%$ of jobs seekers use the internet to find job opportunities. Top 100 companies of 2003 ranked by Fortune magazine use a form of e-recruitment to announce their vacant posts (Lee, 2005). Almost 33\% of organizations use web-based interactive screening tools in present era (Hausdorf and Ducan, 2004). Nonetheless, the fame of e-recruitment is increasing among organizations due to the cost reduction inside of applicant pool proficiently (Leonard, 2000). Most organizations have their own websites which are an effective way to provide authentic information about organizations (Bingham et al., 2002; Epstein and Singh, 2003). Some organization uses their own official websites to recruit employees and some firms have started delivering e-recruitment services (Dixon, 2000). E-recruitment came to the fore as a better tool for communication (Mooney, 2002). Hence, the interaction between job seekers and corporations could be enhanced using erecruitment strategy.

Zusman and Landis (2002) conducted a study with the objective to measure the degree to which candidates favored web-based occupation postings over conventional paper-based materials. The results of this study show that graduates prefer high-quality websites and internet-based ads. Web quality is also discussed in another study titled "The Impact of Web Quality and Playfulness on Users Acceptance of Online Retailing". The results of the analysis of this study demonstrate that playfulness has great importance in enhancing user's intention to use a website of online retailing. The result also shows that a high quality of website encourages usage (Ahn et al., 2007).

The word "SITEQUAL" refers to the quality of a website. The word is taken from the study conducted by Yoo et al. (2001). The objective of this study is to build up an authentic psychometrically rigorous instrument by which the perceived quality of online shopping websites could be measured. The author named the quality of websites as "Sitequal". The results of this study show that the quality of a website affects the human behavior to use websites. Web quality is also discussed in the study of Ahn et al. 
(2007) and results indicate that playfulness has great importance in enhancing user's intention to use the website of online retailing. The result also shows that high quality of website encourages user for its use.

The point of departure of this study is to examine the e-recruitment effects on organizational attraction through mediating variable of cost effectiveness and ease of use. Beside this, this study also explores the relationship between e-recruitment and organizational attraction through moderating variable of Site Quality.

\section{RESEARCH BACKGROUND}

Organizational attraction is a multidimensional and an extremely confusing subject that has been talked about last twenty years. Tsai and Yang (2010) stated Organizational attraction as the willingness of candidates to seek after occupations and to acknowledge employment offers in an organization. As per Highhouse et al. (2003) Organizational attraction is reflected in people by full of feeling and attitudinal considerations about specific organizations as potential spots for business. Ehrhart and Ziegert (2005) stated Organizational attraction as getting a potential worker to view the employer as a positive work environment.

Recruitment ads and organizational attractiveness connection is an alternate subject at issue as of late (Highhouse, 2003; Blackman, 2006; Hoye and Lievens, 2005). The decision of potential applicants to apply for the job could be affected by source/medium of recruitment (Blackman, 2006). Hoye and Lievens (2005) explain that recruitment-related data sources and their characteristics can be essential forerunners of organizational attractiveness. Both internal and outer recruitment sources have an impact on job hunters' attraction towards the organization and their potential employment decisions.

The most powerful social network in this world is the internet. Our society is affected by internet and globalization process as well as. Current statistics show that internet is being used in service sectors worldwide. In Pakistan, the use of internet in job searching is supposed unusual. There are five motivating variables are considered. The leading variable is time-saving and others are "browsing wide area of employment", "Global employment pool", easiness and cost-effectiveness. These motivating variables encourage candidates to go online job search for a job. Author advised private organizations to emphasize on E- Recruitment because it attracts the pool of potential candidates by saving time and gaining much profit (Khan et al., 2013. The Internet is the effective way to attract target labor market for some special posts. There are some specific websites for special audiences. Like asia-net.com only attracts only Asian language speakers.(Galanaki, 2002).

Thomson et al. (2008) conducted a study on the topic of "E- Recruitment and the benifits of organizational web appeal". Their study scrutinized the relationship between organization website designed and job seekers 'attraction. Study found both the attraction of formatting and online recruitment features usability affects the job seekers preferences to peruse employment, but the formatting has a greater importance than usability.

Zusman and Landis (2002) conducted a study on the topic of "Applicant preferences for Web-based versus traditional job postings". The objective of this study was to evaluate the degree to which candidates favored Web-based occupation postings to conventional paper-based materials. Two hypotheses were developed for this study. First and foremost, it was expected that the candidates will prefer Web-based job ads on conventional paper ads. Second, It was expected that the ads publish on the higher quality website is would be preferred on the ads publish on lower quality websites by applicants. Information gathered from 92 college students gave backing to the second theory. The expected results are received by the graduates. They prefer high-quality websites and internet-based 
ads.

Another study was conducted on the topic of "integrating user-perceived quality into Web server design". This study states that as the quantity of Web clients and the different qualities of Web applications keeps on exploding, Web Quality of Service (QoS) is an undeniably basic issue in the area of E- Business. The objective of this study is to assess the user's patience of QoS in E- Commerce perspective. Notwithstanding target measures, the study discusses logical components that impact these edges and indicate how clients' theoretical models of Web errands influence their desires. We then demonstrate how client edges of resilience can be considered when outlining Web servers. This mix of client prerequisites for QoS into frameworks configuration is at last of profit to all stakeholders in the outline of Internet administrations (Bhatti et al., 2000).

Web quality is also discussed in another study on the topic of "The Impact of Web Quality and Playfulness on Users Acceptance of Online Retailing". The main objective of this study is to examine that playfulness has great importance in enhancing user's intention to use the website of online retailing. The result also shows that high quality of website encourages user for its use (Ahn et al., 2007).

The reviews of these studies illustrate that there may be a relationship between organizational attraction and E-Recruitment. Existing literature also shows that cost-effectiveness and userfriendliness of recruitment website can mediate E-recruitment and organizational attraction association. Furthermore, by the literature's review of site quality, the researcher came to know that there is a significant relationship between users' behavior and the quality of a website. This factor encourages the researcher to investigate the same relationship during the E-recruitment process. Thus, the main objectives of this study are to investigate the association between E-recruitment and organizational attraction and to examine how cost-effectiveness, ease of use, and site quality (Sitequal) moderates the association between E-recruitment and organizational attractions. Moreover, the current study research framework is depicted in Figure 2.

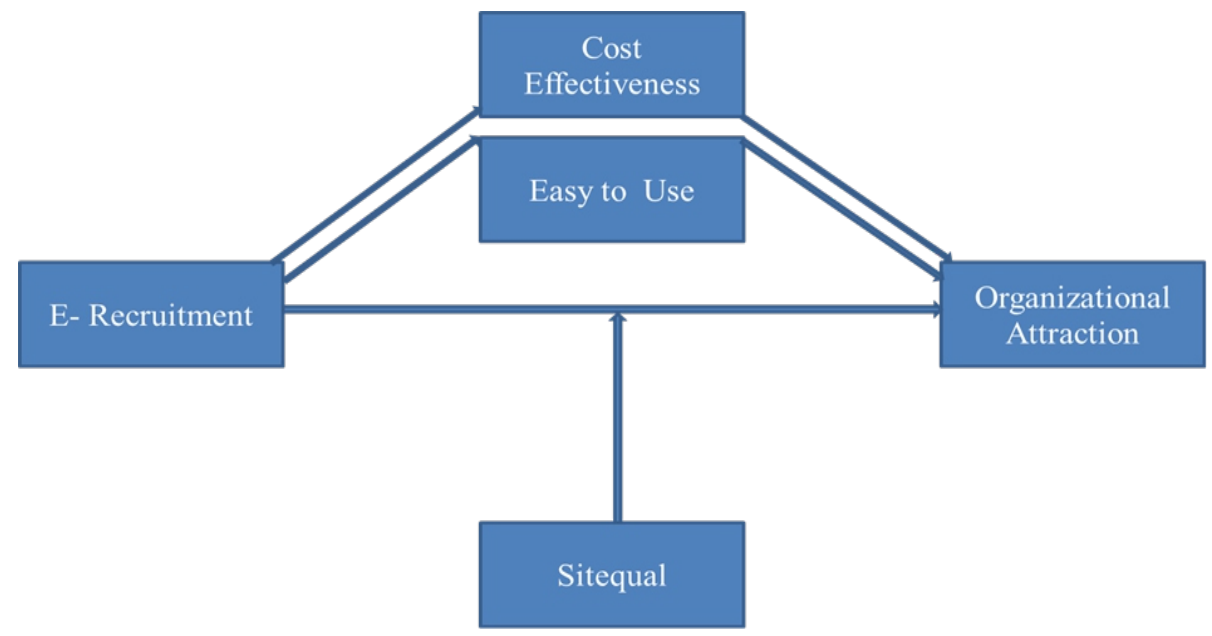

Figure .2: Research Framework

\section{RESEARCH METHODOLOGY}

The target population of present research work consisted of business graduates from various business schools/colleges/institutes/departments or centers of all universities of Lahore. The Higher Education Commission of Pakistan recognized centers were chosen as sample. While those students were 
selected who were in final and second last semesters because they were highly looking for job opportunities. In this way we have selected last two semesters of business scholars as population. We visited the seventeen business schools to collect data. 340 questionnaires were distributed in order to collect data and 302 respondents returned questionnaire with their precious response. While thirty eight respondents didn't respond in this regard. So, the response rate of our survey was $88.82 \%$. This study has taken business schools of Lahore as strata. Stratified random sampling technique was used to choose sample size from concerned strata.

$$
S=\frac{N}{\left(1+N x^{2}\right)}
$$

Where, $\mathrm{N}$ denotes population, $\mathrm{S}$ sample size and $\mathrm{x}$ indicates precision level. Confidence level and precision level are used to determine the sample size of study undertaken. Thus with $94 \%$ confidence level and $6 \%$ precision rate, the sample size of the study is

$$
S=\frac{N}{\left(1+N x^{2}\right)}
$$

Since, $\mathrm{N}=9012$ and $x=0.06$

$$
S=\frac{9012}{\left(1+9012\left(.06^{2}\right)\right.}=269
$$

Thus the sample should be at least 269 respondents from different business schools; however, we have selected 302 respondents. To determine the sample size of each stratum the proportional allocation technique was used. The concerned formula utilized for current purpose is given below:

$$
S_{h}=\frac{S N_{h}}{N}
$$

Where $\mathrm{N}_{\mathrm{h}}$ the population is size of $\mathrm{h}^{\text {th }}$ stratum and $\mathrm{S}_{\mathrm{h}}$ is the sample size of $\mathrm{h}^{\text {th }}$ stratum. The data is collected by using a structured questionnaire, which is comprised of 24 questions. First, three items measured the demographic variable and rest of 21 items measure the dependent ad independent variable of this study. The questionnaire was adopted from two different studies. Some questions are taken from a study titled "exploring the association of e recruitment with organizational attraction and mediating role of cost effectiveness \& easy to use Hafeez and Umar (2016)", and other questions are taken from the study on the topic of "developing a scale to measure the perceived quality of an internet shopping site Yoo et al. (2001). All questions are developed by following the five point Likert scales.

\section{ANALYSIS}

\section{Reliability test}

Mostly, alpha reliabilities over 0.70 are viewed as great when estimated are utilized is substantial

\begin{tabular}{|c|c|c|}
\hline \multicolumn{3}{|l|}{ Reliability Statistics } \\
\hline Variable & Cronbach's Alpha & $\mathrm{N}$ of Items \\
\hline E- Recruitment & 0.858 & 3 \\
\hline Organizational Attraction & 0.829 & 3 \\
\hline Cost Effectiveness & 0.853 & 3 \\
\hline Easy to use & 0.881 & 4 \\
\hline Sitequal & 0.665 & 7 \\
\hline
\end{tabular}
study. The instruments utilized as a part of essential research have solid of around 0.70 or better for this case (Nunnally, 1978). The Cronbach's alpha value of present study is given as below.

Table. 1: Reliability Test 
As appeared in Table 1, the Cronbach's alpha for all items is greater than 0.80 which is exceptionally good. But the estimation of Cronbach's alpha of sit equal is 0.665 , which is lower than 0.70 yet great and since this is a moderating variable, and in a few items the respondents demonstrates the low quality of sites which influenced the Cronbach's alpha.

\section{Sample Kolmogorov-Smirnov test}

The purpose of this test is to check the normality of collected data for T-test. So, 1 sample K-S analysis was run on 21 questions out of 24 questions. First, we split the data file with to compare the group based on Recruitment sources. The results are shown in table given below.

Table. 2: One-Sample Kolmogorov-Smirnov Test

\begin{tabular}{|l|l|l|l|l|l|}
\hline \multicolumn{2}{|l|}{ One-Sample Kolmogorov-Smirnov Test } & Cost Effectiveness & $\begin{array}{l}\text { Organizational } \\
\text { Attraction }\end{array}$ & Easy to Use & Sitequal \\
\hline Source of Recruitment & Asymp. Sig. (2-tailed) & .000 & .000 & .000 & .001 \\
\hline E- Recruitment & Asymp. Sig. (2-tailed) & .111 & .014 & .148 & \\
\hline Newspaper & Asymp. Sig. (2-tailed) & .047 & .407 & .902 & \\
\hline $\begin{array}{l}\text { Friends/Relative } \\
\text { Reference }\end{array}$ & Asymp. Sig. (2-tailed) & .138 & .384 & .907 & \\
\hline Other &
\end{tabular}

As in Table 2, 1 sample K-S test shows that the significant value of each variable on the basis of recruitment source is different in different categories; it shows that data is not normal for T-test. So, the Kruskill Wallis test will be applied on data for further testing.

\section{Testing of hypothesis Kruskill Wall is test}

Before moving toward, the analysis, the reader should keep one thing in his/her mind that the questionnaire is developed by following the five point likert scale: $1=$ Strongly Agree, $2=$ Agree, $3=$ Neutral, 4= Disagree and 5= Strongly Disagree. As the highest point 5= Strongly Disagree which shows that highest mean scores will show the poor association between variables and, on the other hand, lowest point $1=$ Strongly Agree which shows that lowest mean scores will show the strong association/ Positive relationship between the tested variables.

Table .3: Descriptive Statistics of Hypothesizes

\begin{tabular}{|l|l|l|l|l|l|}
\hline Descriptive Statistics & $\mathrm{N}$ & Mean & Std. Deviation & Minimum & Maximum \\
\hline Organizational Attraction & 302 & 2.0088 & 1.07039 & 1.00 & 5.00 \\
\hline Source of Recruitment & 302 & 1.4338 & .77797 & 1.00 & 4.00 \\
\hline Cost Efficiency & 302 & 2.0442 & 1.12305 & 1.00 & 5.00 \\
\hline Source of Recruitment & 302 & 1.4338 & .77797 & 1.00 & 4.00 \\
\hline Easy to Use & 302 & 2.0058 & 1.07010 & 1.00 & 5.00 \\
\hline Source of Recruitment & 302 & 1.4338 & .77797 & 1.00 & 4.00 \\
\hline Easy to use & 212 & 1.3443 & .29501 & 1.00 & 3.25 \\
\hline Sitequal & 212 & .5189 & .50083 & .00 & 1.00 \\
\hline Organizational Attraction & 212 & 1.3774 & .31822 & 1.00 & 2.33 \\
\hline Sitequal Mean & 212 & .5189 & .50083 & .00 & 1.00 \\
\hline
\end{tabular}

Note: Table 3 shows the descriptive statistic of all hypothesizes. 
Table .4:Test Statistics

\begin{tabular}{|c|c|c|c|c|c|}
\hline \multicolumn{2}{|c|}{ Test Statistics } \\
\hline & $\begin{array}{c}\text { Organizational } \\
\text { Attraction w.r.t } \\
\text { Recruitment } \\
\text { sources }\end{array}$ & $\begin{array}{c}\text { Cost } \\
\text { Effectiveness } \\
\text { w.r.t } \\
\text { Recruitment } \\
\text { sources }\end{array}$ & $\begin{array}{c}\text { Easy to Use } \\
\text { w.r.t } \\
\text { Recruitment } \\
\text { sources }\end{array}$ & $\begin{array}{c}\text { Easy to use } \\
\text { w.r.t sitequal }\end{array}$ & $\begin{array}{c}\text { Organizational } \\
\text { Attraction w.r.t } \\
\text { sitequal }\end{array}$ \\
\hline Chi-Square & 190.345 & 202.781 & 193.524 & 5.047 & 7.614 \\
\hline Df & 3 & 3 & 3 & 1 & 1 \\
\hline $\begin{array}{c}\text { Asymp. } \\
\text { Sig. }\end{array}$ & 0 & 0 & 0 & 0.025 & 0.006 \\
\hline
\end{tabular}

Note: Table 4 shows the test statistics of all variables.

Table .5:Ranks of Hypothesis I

\begin{tabular}{|l|l|l|l|}
\hline \multicolumn{3}{|c|}{ Rank } \\
\hline \multirow{4}{*}{ Organizational Attraction } & Source of Recruitment & N & Mean Rank \\
\cline { 2 - 4 } & E-Recruitment & 212 & 108.22 \\
\cline { 2 - 4 } & Newspaper & 62 & 253.74 \\
\cline { 2 - 4 } & Friend/Relatives Refererals & 15 & 254.63 \\
\cline { 2 - 4 } & Other & 13 & 2500.73 \\
\cline { 2 - 4 } & Total & 302 & \\
\hline
\end{tabular}

As we found in Table 5, the mean scores of E-recruitment are lower than the mean scores of Newspaper/Friends and Relatives Referrals/others. This means that organizational attraction is positively affected by E-recruitment and it also shows that the positive association between Erecruitment and organizational attraction is stronger than the association among organizational attraction \& Newspaper/Friends and Relatives Referrals/ others. In other words, we can say that job seekers perceive that E- Recruitment system attracts them more than traditional recruitment system.

\section{Table .6: Ranks of Hypothesis II}

\begin{tabular}{|c|c|c|c|}
\hline \multicolumn{4}{|c|}{ Ranks } \\
\hline & Source of Recruitment & $\mathrm{N}$ & Mean Rank \\
\hline \multirow[t]{5}{*}{ Cost Effectiveness } & E- Recruitment & 212 & 106.87 \\
\hline & Newspaper & 62 & 254.69 \\
\hline & Friends/ Relative Referrals & 15 & 254.70 \\
\hline & Other & 13 & 268.15 \\
\hline & Total & 302 & \\
\hline
\end{tabular}

As we found in Table 6, the mean scores of E-recruitment are lower than the mean scores of Newspaper/Friends and Relatives Referrals/others. This means that Cost Effectiveness is positively affected by E-recruitment and it also shows that the positive association between E-recruitment and Cost Effectiveness is sturdier than the relationship between Cost Effectiveness and Newspaper/Friends and Relatives Referrals/ others. In other words, we can say that job seekers perceive that an E-recruitment system saves their money as compared to traditional recruitment systems. The Study of Maurer and Liu (2007) supports this result. According to their study ERecruitment saves the cost and time of the job seeker. 


\begin{tabular}{|c|c|c|c|}
\hline \multicolumn{2}{|c|}{ Ranks } & Mean Rank \\
\hline \multirow{3}{*}{ Easy to Use } & Source of Recruitment & $\mathrm{N}$ & 107.07 \\
\cline { 2 - 4 } & E- Recruitment & 212 & 256.08 \\
\cline { 2 - 4 } & Newspaper & 62 & 258.63 \\
\cline { 2 - 4 } & Friends/ Relatives Referrals & 15 & 253.62 \\
\hline
\end{tabular}

Table .7:Ranks of Hypothesis III

As we found in Table 7, that the mean scores of E-recruitment are lower than the mean scores of Newspaper/Friends and Relatives Referrals /others. It means that ease of use is positively affected by E-recruitment and it also shows that the positive relationship between E-recruitment and Ease of use/access is stronger than the relationship between organizational attraction and Newspaper/Friends and Relatives Referrals/ others. In other words, we can say that job seekers perceive that an Erecruitment system is easier to use for job seekers as compared to traditional one.

Table. 8:Ranks of Hypothesis IV

\begin{tabular}{|c|c|c|c}
\hline \multicolumn{4}{|c}{ Ranks } \\
\hline & Sitequal & $\mathrm{N}$ & Mean Rank \\
\hline \multirow{3}{*}{ Easy to use } & High Sitequal & 102 & 97.38 \\
\cline { 2 - 4 } & Low Sitequal & 110 & 114.95 \\
\cline { 2 - 4 } & Total & 212 & \\
\hline
\end{tabular}

As we found in Table 8, that the mean scores of high sitequal are lower than the mean scores of low sitequal. This means that the job seekers who used the E-recruitment websites with high quality are shown that the use of E-recruitment websites is easy as compared to the job seekers who used Erecruitment websites with low quality websites.

Table. 9: Ranks of Hypothesis V

\begin{tabular}{|c|c|c|c|}
\hline \multicolumn{4}{|c|}{ Ranks } \\
\hline & Sitequal & $\mathrm{N}$ & Mean Rank \\
\hline \multirow{3}{*}{ Organizational Attraction } & High Sitequal & 102 & 95.98 \\
\cline { 2 - 4 } & Low Sitequal & 110 & 116.26 \\
\cline { 2 - 4 } & Total & 212 & \\
\hline
\end{tabular}

Table 9 shows that the $p$ value of organizational attraction w.r.t sitequal is less than the 0.05 . It shows that there is an association between Sitequal (Quality of E- Recruitment web sites) and organizational attraction. Table 9 shows that the mean scores of low sitequal is 116.26 and high sitequal is 95.98 . We found that the mean scores of high sitequal are lower than the mean scores of low sitequal. This means that the job seekers who used the E-recruitment websites with high quality are attracted towards the organization more than the job seekers who used E-recruitment websites with low quality websites. So, it shows that sitequal moderates the relationship between E-recruitment and organizational attraction. 
Testing hypothesis by using regression analysis

Table .10: Regression Analysis for Mediator I

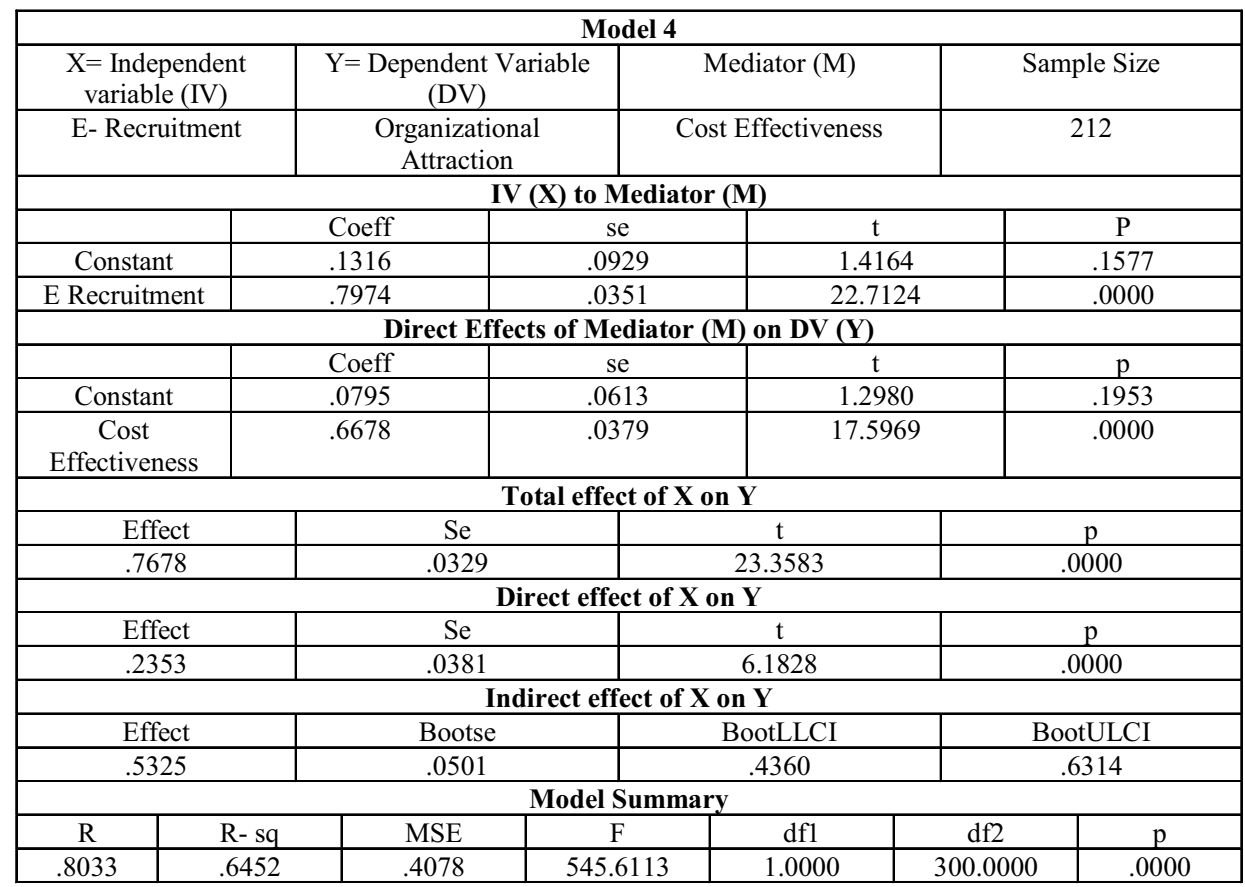

As Table 10 shows that Macro process tool for Regression analysis was used to examine the hypothesis stated that cost effectiveness mediates the relationship between E-recruitment and organizational attractiveness. Results show that E-recruitment is a noteworthy predictor of cost effectiveness, $\mathrm{b}=.7974, \mathrm{SE}=.929, \mathrm{p}<.05$, and that cost effectiveness is a significant indicator of organizational attraction, $\mathrm{b}=.6678, \mathrm{SE}=.0379 \mathrm{p}<.05$. These outcomes support the mediational hypothesis. E-recruitment has no any significant impact on organizational attraction after controlling cost effectiveness, $\mathrm{b}=.235, \mathrm{SE}=.0381$, consistent with full mediation. Around $65 \%$ of the change in organizational attraction is represented by the predictors $(\mathrm{R} 2=.645)$. The indirect impact was analyzed by using a bootstrap estimation method with 1000 samples. The findings demonstrate that the indirect coefficient is significant, $\mathrm{b}=.532, \mathrm{SE}=.0501,95 \% \mathrm{CI}=.4360, .6314$. Thus, Erecruitment related with about .53 points higher organizational attraction scores as mediated by cost effectiveness 
IBT Journal of Business Studies

Table .11: Regression Analysis for Mediator II

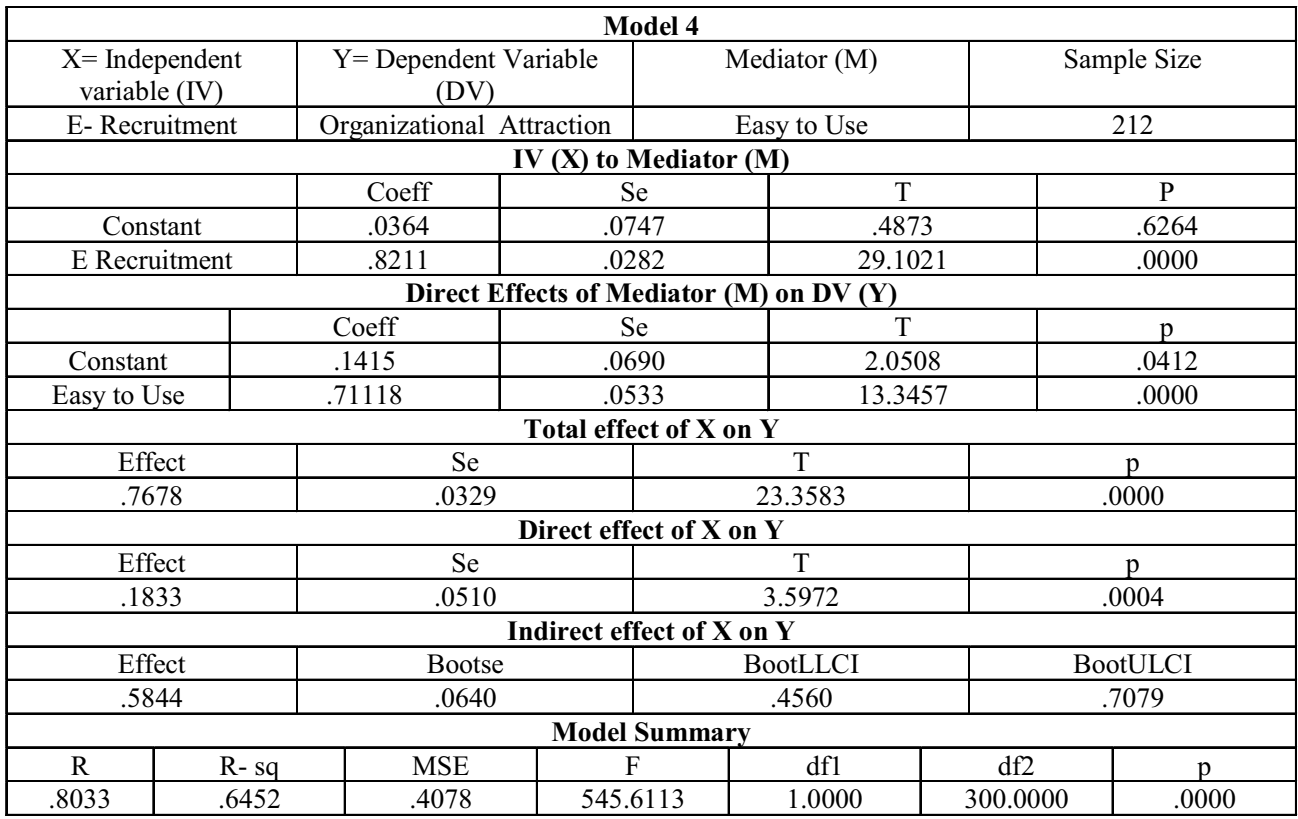

Table 11 demonstrates that macro process tool for regression analysis was utilized to examine the hypothesis stated that ease of use mediates the relationship between E-recruitment and organizational attractiveness. Findings demonstrate that E- Recruitment is a significant predictor of ease of use, $\mathrm{b}=$ $.821, \mathrm{SE}=.0282, \mathrm{p}<.05$, and that ease of use is a noteworthy prognosticator of organizational attraction, $\mathrm{b}=.711, \mathrm{SE}=.0533 \mathrm{p}<.05$. These results support the mediational hypothesis. $\mathrm{E}-$ recruitment has no any significant impact on organizational attraction after controlling the mediator, ease of use, $\mathrm{b}=.1833, \mathrm{SE}=.0510$, consistent with full mediation. Around $65 \%$ of the variance in organizational attraction is due to the predictors $(\mathrm{R} 2=.645)$. The indirect impact was analyzed by using a bootstrap estimation method with 1000 samples. These results demonstrate that the indirect coefficient is significant, $\mathrm{b}=.584, \mathrm{SE}=.0640,95 \% \mathrm{CI}=.4560, .7079$. Thus, E-recruitment related with about .58 points higher organizational attraction scores as mediated by ease to use. 
Table .12: Regression Analysis for Moderator

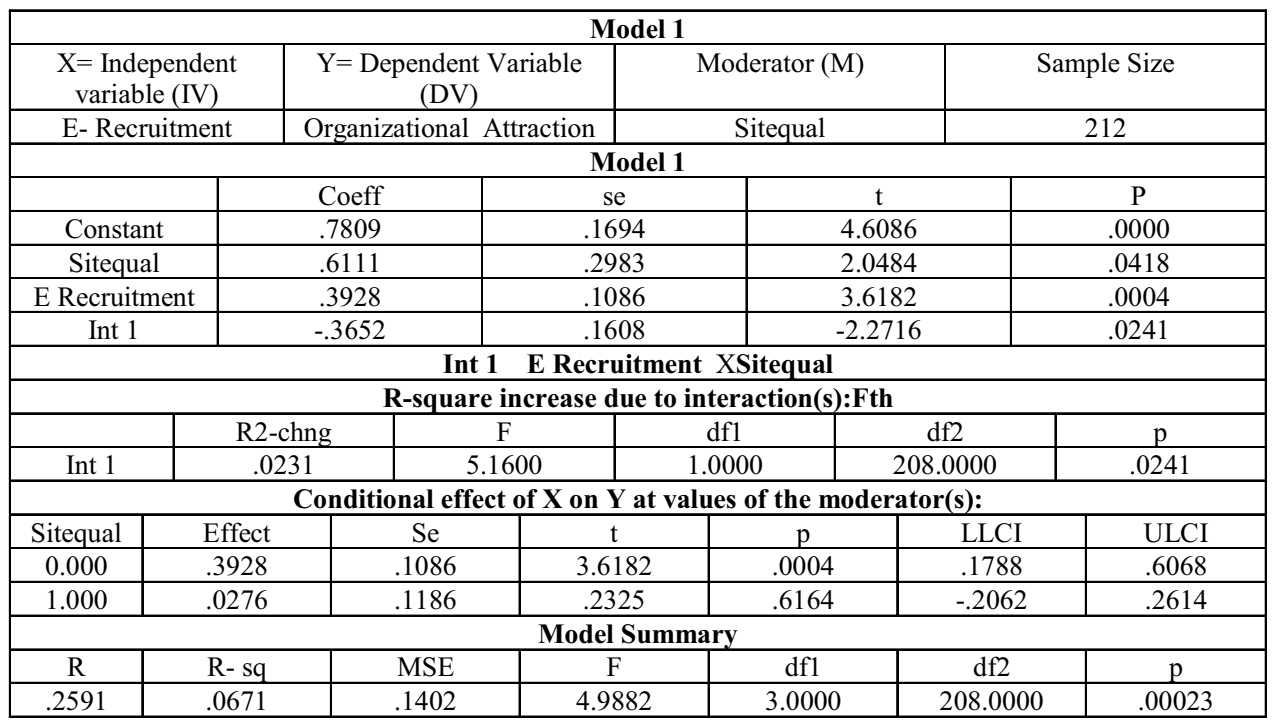

As appeared in Table 12, the Macro process tool for Regression analysis is utilized to examine the hypothesis stated that sitequal (site quality) moderates the relationship between E-recruitment and organizational attraction. Analysis outcomes demonstrate that Int 1 is significant, $\mathrm{R} 2$ change $=.0231$, $\mathrm{F}=5.1600, \mathrm{p}<.05$. The outcomes support the moderating hypotheses. Outcomes of provisional effect of $\mathrm{X}$ on $\mathrm{Y}$ demonstrate that in case of high site quality which denoted by 0.000 E-recruitment and organizational attraction are significantly associated as Effect $=.3928 \mathrm{SE}=.1086, \mathrm{t}=3.6182$ and $\mathrm{p}<$ 0.05. Furthermore, with reference to 1.000 which indicates low sitequal E-recruitment and organizational attraction are not significantly associated as Effect $=.0276 \mathrm{SE}=.1186, \mathrm{t}=0.2325 \& \mathrm{p}>$ 0.05 . The model summary demonstrates that the model of study undertaken is significant. Thus, the results demonstrate that sitequal moderates the relationship between E-recruitment and organizational attraction.

\section{FINDINGS AND RECOMMENDATIONS}

In this study, e-recruitment is definitely showing as a positive indicator for organization attraction. Reliability analysis showed that the data was valid, as all the variables used in study undertaken have more than 0.8 Cronbach's alpha value which is exceptionally good except the value of sitequal which is 0.66 which was acceptable but it is less than 0.7 due to the moderating role of sitequal. This reveals that there is no gap between questions and all 21 questions are reliable and valid to run the statistical test. As 1 sample Kolmogrov-Smirnov test showed that data was not normal for T-test. So the Kruskill Wallis test was used for further analysis. The overall results of the Kruskill Wallis test reveals that the majority of job seekers have almost the same opinions. Most of the job seekers perceived that Erecruitment systems save their money by mitigating the cost of registry/courier/application form and travelling. The Kruskill Wallis test also showed that E-recruitment websites can be used and accessed easily as compared to traditional recruitment systems. The results of this test showed that applicants are more attracted towards E-recruitment systems instead of traditional recruitment systems, but there is a factor that can affect this attraction, that factor is the quality of websites. The Kruskill Wallis test also reveals that the job seekers who have used E-recruitment websites with low web quality show less attraction towards E-recruitment as compared to job-seekers who have been using E-recruitment websites with high quality. 
Regression Analysis also supports the findings of the Kruskill Wallis Test. Results of regression analysis reveals that E-recruitment is positively related to organizational Attraction. Furthermore, the relationship between e-recruitment and Organizational Attraction is mediated by Cost Effectiveness and Ease to use. The Concluding remarks of regression analysis reveal that an e-recruitment system enhances the attraction of an organization but the quality of e-recruitment Websites can affect this relationship. As the quality of websites is the most important factor that can decrease or increase the charm of E-Recruitment, it is recommended for organizations to focus on the quality of websites to retain its effectiveness.

Consequently, a summary of this analysis revealed that e-recruitment and organizational attraction are significantly associated. Additionally, cost effectiveness and ease to use mediates and sitequal moderates the relationship between e-recruitment and organizational attraction. On the basis of these results, we can also establish and acquire new standards of organization attraction through a continuous use of e-recruitment strategy. So, on the basis of the findings of Kruskill Wallis test and regression analysis it is recommended to the organization to adopt an e-recruitment system as it attracts job seekers towards the organization but they should concentrate on the quality of the websites.

\section{CONCLUSION}

This study shows that e-recruitment and organizational attraction reveals significant association among these variables. The purpose current study was to ascertain this relationship in presence of cost effective and ease of use of E-recruitment as mediating variables and website quality as being moderator variable. To guide this investigation, three research questions are developed. Firstly, this study aims to observe job seekers' perceptions towards e-recruitment systems. Secondly, we aim to measure the effectiveness of e-recruitment in attracting potential job candidates. Lastly, this study also examines the intermediating role of cost effectiveness and user-friendliness of recruitment website on the association between e-recruitment and organizational attraction.

In depth analysis of primary data which is gathered using close-ended questionnaire consisting of 18 questions is performed to explore the association between e-recruitment and organizational attraction among job seekers. The findings from this study provide substantial evidence to answer research questions and provide valuable input in the literature. The findings of this research work depict that erecruitment frameworks positively affect prospective employees which enhance the attraction of an organization. Thus, study shows that e-recruitment can be used easily and spares the cash of employment searchers. It is discovered that an e-recruitment System positively affects cost saving and usability and these variables improve the connection between e-recruitment and organizational fascination. This implies that the companies which adapt an e-recruitment strategy are considered more attractive among employment searchers and, because of the pros of e-recruitment and the ensuing conspicuousness of the organization, skillful employment searchers will like to join that organization. The study found that the quality of the websites affects the attraction of the organization. Low quality of recruitment websites has a negative impact on organizational attraction. By analyzing the data, thus we conclude that there is positive association between E- Recruitment and organizational attraction but the quality of recruitment websites can affect this relationship. So, organizations should adopt e-recruitment systems but at the same time they should focus websites' quality to maintain the job seekers attraction.

Results from this study confirm findings of previous studies in terms of cost effectiveness and userfriendliness of e-recruitment systems. Hafeez and Umar (2016) report mediating role of cost effectiveness and ease of use on the relationship between e-recruitment and organizational attraction. According to Thompson et al. (2008) both the attraction of formatting and online recruitment features usability affects the job seekers preferences to peruse employment, but formatting has a greater importance than usability. Further, this study adds a novel contribution in e-recruitment literature by introducing website quality as moderating variable which strengthens the association between e- 
recruitment and organizational attraction.

This paper suggests that the human resource specialists and policy makers need to opt E-recruitment framework to be a magnet for job seekers. Executing e-recruitment strategies can give huge advantages to organizations. This study demonstrates that each organization that aims to meet its objectives and increase upper hands need to opt said e-recruitment framework. The decisions and the policies of management of any organization can affect the activities in the organization. So, management should make the right decisions at the right time to achieve their organization's goals efficiently and effectively. Today, information technology is involved in almost all the processes and activities of the world. This is the age of information era, so this is the right time for human resource managers to implement e-recruitment systems to hire the competent workers.

\section{REFERENCES}

Anonymous (2000). Online recruiting: what works, what doesn't. HR Focus, 3, 11-13.

Ahn, T., Ryu, S., \& Han, I. (2007). The impact of web quality and playfulness on user acceptance of online retailing. Information \& Management, 44(3), 263-275.

Bhatti, N., Bouch, A., \& Kuchinsky, A. (2000). Integrating user-perceived quality into Web server design. Computer Networks, 33 (1-6), 1-16.

Bingham, B., Ilg, S., \& Davidson, N. (2002). Great candidates fast: On-line job application and electronic processing. Public Personnel Management, 31(1), 53-64.

Blackman, A. (2006). Graduating students' responses to recruitment advertisements. Journal of Business Communication, 43(4), 367-388.

Collins, C. J., \& Han, J. (2004). Exploring applicant pool quantity and quality: The effects of early recruitment practice strategies, corporate advertising, and firm reputation. Personnel Psychology, 57(3), 685-717.

Cullen, B. (2007). e- Recruiting is driving HR system integration. Strategic Finance, 83(1), 22-26.

Dessler, G. (2001). A framework for human resource management (2nd ed.). Harlow, United Kingdom: Prentice Hall.

Dineen, B. R., Noe, R. A., \& Wang, C. (2004). Perceived fairness of web-based applicant screening procedures: Weighing the rules of justice and the role of individual differences. Human Resource Management, 43(2-3), 127-145.

Dixon, P. (2000). Job searching online for dummies (2nd ed.). New York, NY, United States: Hungry Minds Inc,U.S.

Epstein, R., \& Singh, G. (2003). Internet recruiting effectiveness: Evidence from a biomedical device firm. International Journal of Human Resources Development and Management, 3(3), 216.

Ehrhart, K., \& Ziegert, J. (2005). Why Are Individuals Attracted to Organizations. Journal of Management, 31 (6), 901-919.

Galanaki, E. (2002). The decision to recruit online: A descriptive study. Career Development Internatioal, 7 (4), 243-251.

Hafeez, M., \& Farooq, U. (2016). Exploring the association of e-recruitment with organizational attraction and mediating role of cost effectiveness \& easy to use. Sci.Int.(Lahore), 28(2), $1651-1657$.

Hausdorf, P. A., \& Duncan, D. (2004). Firm size and Internet recruiting in Canada: A preliminary investigation. Journal of Small Business Management, 42(3), 325-334.

Highhouse, S., Lievens, F., \& Sinar, E. (2003). Measuring attraction to organizations. Educational and Psychological Measurement, 63 (6), 986-1001.

Hoye, V., \& Lievens, F. (2005). Recruitment-Related Information Sources and Organizational Attractiveness: Can Something Be Done About Negative Publicity. International Journal of Selection and Assessment, 13 (3), 179-187.

Khan, N. R., Awang, M., \& Ghouri, A. M. (2013). The impact of E- Recruitment and job seekers 
perceptions on the intention to pursue the jobs. Management \& Marketing, XI(1), 48-57.

Lee, I. (2005). The evolution of e-recruiting: A Content Analysis of Fortune 100 Career Web Sites. Journal of Electronic Commerce in Organizations, 3(3), 57-68.

Leonard, B. (2000). Online and overwhelmed. HR magazine, August, 45(8), . Retrieved from https://www.shrm.org/hr-today/news/hr-magazine/pages/0800cov.aspx

Maurer, S. D., \& Liu, Y. (2007). Developing effective e-recruiting websites: Insights for managers from marketers. Business Horizons, 50(4), 305-314.

Mooney, J. (2002). Pre-Employment testing on the Internet: Put candidates a click away and hire at modem speed. Public Personnel Management, 31(1), 41-52.

Musa, N., Junaini, S. N., \& Bujang, Y. R. (2006). Improving Usability of E-recruitment Website : A Preliminary Study on Sarawak Government Website. Study Background, (Pacis), 507-515

Nunnally, J. C. (1978). Psychometric theory (2nd ed.). New York: McGraw-Hill Inc.,US.

Rakholiya, N., \& Gupta, C. (2013). A study on the Applicant's Perception towards E-recruitment. View of Space: International Multidisciplinary Journal of Applied Research, 1(1), 50-53.

Smith (2005). Finding the right people just got easier. Retrieved November 20, 2016, from $\mathrm{http}$ ://www.franchise.org/finding-the-right-people-just-got-easier

Thomson, L. F., Braddy, P. W., \& Wuensch, K. L. (2008). E- Recruitment and the benifits of organizational web appeal. Computer in human behavior , 2384-2398.

Tong, D. Y. K., \& Sivanand, C. N. (2005). E-recruitment service providers review. Employee Relations, 27(1), 103-117.

Tsai, W.-C., \& Yang, I. W.-F. (2010). Does image matter to different job applicants? The influences of corporate image and applicant individual differences on organizational attractiveness. International Journal of Selection and Assessment, 18(1), 48-63.

Hoye, G., \& Lievens, F. (2005). Recruitment-related information sources and organizational attractiveness: Can something be done about negative publicity? International Journal of Selection and Assessment, 13(3), 179-187.

Yoo, B., \& Donthu, N. (2001). Developing a scale to measure the perceived quality of an Internet shopping site (PQISS). Quarterly Journal of Electronic Commerce, 2(1), 31-47.

Zusman, R. R., \& Landis, R. S. (2002). Applicant preferences for web-based versus traditional job postings. Computers in Human Behavior, 18(3), 285-296. 